\title{
MEDIA PROMOSI PERILAKU HIDUP BERSIH DAN SEHAT (PHBS) DI KAWASAN WISATA DANAU TOBA
}

\author{
${ }^{1}$ Destanul Aulia, ${ }^{2}$ Sri Fajar Ayu \\ ${ }^{1}$ Fakultas Kesehatan Masyarakat, Universitas Sumatera Utara \\ Jalan Universitas No. 21, Medan \\ aulia_destanul@yahoo.com \\ ${ }^{2}$ Fakultas Pertanian, Universitas Sumatera Utara \\ Jalan Dr. A Sofyan No. 3 Kampus USU, Medan \\ srifajar.ayu@gmail.com
}

\begin{abstract}
Human resources in Lake Toba should be built along with the attention and development of natural tourism potential of Lake Toba, that has been given by the government. One of the steps is through education about clean and healthy behavior. This education can be done through the promotion of clean and healthy life behavior for the people of Lake Toba, both in physical and non-physical form. This program is aimed at promoting clean and healthy living behavior (PHBS) through PHBS promotional media created by involving local potency in Lake Toba by use a community figure, institution / institution like Alusi Tao Toba. The method of implementation of this program is to create a media promotion of PHBS by involving local potential and discussion lecture method for training activities of public figures and institutions about PHBS by using media campaign that has been made. The result of the implementation of this activity is the existence of simple and interesting PHBS manual and given to Alusi Tao Toba. In addition, PHBS promotional videos and PHBS banners for PHBS promotional media have been established in Lake Toba area through a partnership.
\end{abstract}

Keywords: Media of Promotion, Clean and Healthy Living Behavior, Alusi Tao Toba, Video

\section{PENDAhULUAN}

Promosi kesehatan merupakan investasi luar biasa yang secara makro mampu mengurangi kerugian negara akibat terjadinya ganggunan kesehatan bagi masyarakat. Promosi kesehatan memiliki sasaran primer yaitu masyarakat melalui pemberdayaan masyarakat, sasaran sekunder yaitu tokoh masyarakat atau pemuka maupun tokoh dan sasaran tersier yaitu lembagalembaga yang ada di sekitar masyarakat. Pemberdayaan masyarakat dan sumber daya lokal lain merupakan langkah yang efektif dalam mendukung pembangunan kesehatan dan meningkatkan derajat kesehatan masyarakat [1].
Masyarakat lokal akan lebih mudah disentuh melalui hal-hal yang sudah sangat akrab dengan mereka, baik dari segi kekerabatan (sumber daya manusia), adat istiadat, maupun lembaga atau komunitas yang memiliki hubungan langsung dengan masyarakat [2], [3], [4].

Pendidikan kesehatan tidak dapat dengan beranggapan, ataupun menyamakan bahwa setiap orang termotivasi dan belajar hal yang sama. Tidak ada cara yang umum untuk mendidik tentang kesehatan sehingga kita perlu berfikir bagaimana langkah yang paling sesuai dengan keadaan lapangan dalam melakukan pendidikan kesehatan terhadap masyarakat [5]. 
Kawasan Danau Toba selaku objek wisata yang menjadi nilai estetika bagi Sumatera Utara harus dilestarikan dengan serius, Pemerintah pusat juga sedang gencar-gencarnya mempromosikan Danau Toba bahkan menetapkannya sebagai kawasan strategis nasional, namun sedikit kecewa dengan fasilitas kesehatan di Danau Toba yang kontraproduktif [6]. Padahal kesehatan masyarakat dan kesehatan lingkungan merupakan faktor yang sangat penting bagi tourism dalam kemajuan wisata. Hal ini tentu menggambarkan betapa perhatian pemerintah terhadap kesehatan di Danau Toba begitu besar. Tidak hanya menjaga keindahan destinasi wisatanya, namun lebih utamanya adalah menjaga generasi danau toba agar menjadi generasi sehat sebagai investasi masa depan. Generasi sehat lahir dari manusia yang berperilaku bersih dan sehat, sehingga sedini mungkin perilaku untuk hidup bersih dan sehat harus dipupuk kokoh sebagai langkah preventif menghindari penyakit.

Melalui kajian awal dengan menggunakan kuesioner, maka tingkat pengetahuan masyarakat tentang PHBS masih rendah, meskipun beberapa dari mereka sudah memiliki pengetahuan yang banyak tentang PHBS.

Menyelamatkan generasi Danau Toba tentu tidak hanya dengan meningkatkan pendidikan, namun juga melatih mereka untuk berperilaku hidup yang bersih dan sehat. Untuk itu, Yayasan Alusi Tao Toba sudah seharusnya juga memiliki media yang dapat mengajak masyarakat pengguna fasilitasnya untuk mengaplikasikan perilaku hidup bersih dan sehat. Kemudian, juga harus didukung dengan kadernya yang berkompeten dan berkapabilitas mempromosikan perilaku hidup bersih dan sehat agar lebih menyebar. Dengan perilaku hidup bersih dan sehat, maka masyarakat dan generasi Danau Toba tidak hanya cinta membaca, namun mampu lebih produktif dalam membaca karena memiliki tubuh yang sehat.

Keberadaan Alusi Tao Toba sudah sangat bersahabat dengan masyarakat, mengingat beberapa kadernya yang ikut menggerakkan yayasan adalah masyarakat lokal yang berasal dari lingkungan Danau Toba. Hanya saja kegiatan yang dilakukan masih lebih fokus pada peningkatan minat membaca anak-anak. Sementara itu, para penggerak yayasan juga harus sadar bahwa kesehatan adalah investasi pokok untuk mencapai pendidikan dan pekerjaan yang produktif. Selanjutnya mereka juga harus mengajak para masyarakat, baik anak-anak maupun orang dewasa untuk berperilaku hidup bersih dan sehat. Untuk itu, para kader yayasan harus memiliki kompetensi dan kapabilitas untuk mengajarkan perilaku hidup bersih dan sehat (PHBS) melalui berbagai media kepada lingkungan sekitar mereka.

Pemberdayaan tokoh Alusi Tao Toba dan beberapa tokoh masyarakat lainnya merupakan langkah yang strategis dalam meningkatkan pengetahuan masyarakat tentang PHBS dan meningkatkan tingkat adopsi. Pengabdian ini dilakukan dengan menggandeng Alusi Tao Toba dan beberapa masyarakat dalam membuat media promosi PHBS.

\section{METODE}

Kegiatan ini dilaksanakan di Lontung, Kecamatan Simanindo, Kabupaten Samosir. Pemilihan lokasi ini dilakukan secara pusposive karena daerah ini merupakan daerah pertama berdirinya sopo belajar milik yang dikelola Alusi Tao Toba. Adapun program dilaksanakn dengan metode survei dan dokumentasi. Metode survei digunakan untuk menganalisis tingkat pengetahuan masyarakat tentang PHBS. Sementara metode dokumentasi bertujuan untuk mendokumentasikan gambar-gambar yang akan digunakan dalam membuat media promosi.

Setelah media promosi PHBS dibuat, maka dilakukan transfer ilmu pengetahuan tentang PHBS. Kegiatan ini diberikan kepada tokoh Alusi Tao Toba dengan menggunakan metode ceramah dan diskusi. Bertujuan untuk memberikan wawasan berPHBS kepada para kader dan mampu memperagakan dan mengajarkan PHBS kepada masyarakat di lapangan. 
Aulia, D. et al. Media Promosi Perilaku Hidup Bersih Dan Sehat (PHBS) Di Kawasan Wisata Danau Toba

\section{HASIL DAN PEMBAHASAN}

Alusi Tao Toba dibentuk pada 18 Juni 2009. Dalam menjalankan programnya, Alusi Tao Toba membuat 4 buah Sopo Belajar. Sopo adalah istilah untuk bangunan, bangunan ini lah yang dijadikan oleh Alusi Tao Toba sebagai wadah untuk mengumpulkan anak-anak dan masyarakat untuk dekat dengan pendidikan. Sopo belajar yang pertama adalah Sopo Belajar Lontung. Sopo ini terletak di desa Pardomuan, Kecamatan Simanindo.

Pelaksanaan program media promosi ini dilakukan di Desa Pardomuan yaitu lokasi didirikannya Sopo Belajar Lontung. Sopo ini terletak 9 kilometer dari Pelabuhan Tomok dan dapat diakses dengan menggunakan jalan darat.

Perilaku Masyarakat

Strategi PHBS memfokuskan pada lima program prioritas yaitu kesehatan ibu dan anak (KIA), Gizi, Kesehatan Lingkungan, Pencegahan dan Penaggulangan Penyakit Tidak Menular (P2PTM) dan Jaminan Pemeliharaan Kesehatan. Pada tahun 2014 pencapaian rumah tangga ber-PHBS dapat dilihat pada table berikut ini:

Tabel 1. Jumlah Masyarakat PHBS

\begin{tabular}{|l|c|c|c|c|c|}
\hline $\begin{array}{l}\text { Tahu } \\
\mathrm{n}\end{array}$ & RT & $\begin{array}{l}\text { Dipant } \\
\text { au }\end{array}$ & $\begin{array}{c}\% \\
\text { Dipant } \\
\text { au }\end{array}$ & $\begin{array}{c}\text { ber- } \\
\text { PHBS }\end{array}$ & $\begin{array}{c}\% \\
\text { berPH } \\
\text { BS }\end{array}$ \\
\hline 2011 & $\begin{array}{c}29.3 \\
65\end{array}$ & 26.763 & 91,1 & 6.474 & 24,2 \\
\hline 2012 & $\begin{array}{c}29.7 \\
75\end{array}$ & 28.558 & 95,9 & $\begin{array}{c}11.21 \\
3\end{array}$ & 39,3 \\
\hline 2013 & $\begin{array}{c}29.8 \\
85\end{array}$ & 24.224 & 81,1 & $\begin{array}{c}23.39 \\
9\end{array}$ & 99,6 \\
\hline 2014 & $\begin{array}{c}29.7 \\
59\end{array}$ & 16.670 & 56,0 & $\begin{array}{c}16.67 \\
0\end{array}$ & 100 \\
\hline
\end{tabular}

(Sumber: Dinas Kesehatan Samosir, 2014)

Menurut data Profil Kesehatan Kabupaten Samosir, pada tahun 2014 lalu sudah ditemukan 209 rumah tangga yang berPHBS dari 809 yang seharusnya dipantau, sehingga langkah yang akan dilakukan melalui program ini merupakan langkah yang tepat.

\section{Keadaan Lingkungan}

Daerah Lontung terletak +9 kilometer dari Pelabuhan penyeberangan (Tomok). Lokasi yang menjadi tempat kegiatan dapat diakses dengan menggunakan transportasi darat. Akses jalan menuju desa Pardomuan masih belum berbentuk aspal dan dalam pelaksanaan pembangunan jalan. Akses air bersih bagi masyarakat Pardomuan sebagian besar berasal dari sebuah mata air yang terletak di desa tersebut. Air inilah yang digunakan masyarakat untuk memperoleh air minum serta untuk mandi dan mencuci.

\section{Luaran yang Dicapai}

Setelah melaksanakan pengambilan gambar dan video di lokasi, maka diperoleh beberapa gambar yang akan dimuat dalam media promosi PHBS berupa buku dan video.

\section{Video PHBS}

Video PHBS ini dibuat dengan menggunakan beberapa tokoh masyarakat untuk turut serta dalam menjelaskan dan mengajak masyarakat untuk ber-PHBS. Video PHBS dibuat dalam format wmv dan dimasukkan dalam compact disk. Compact Disk yang sudah jadi, diberikan kepada Alusi Tao Toba sebagai media yang digunakan dalam mempromosikan PHBS di Kawasan Danau Toba.

\section{Buku Panduan PHBS}

Sebagaimana mestinya, buku ini memuat 10 unsur PHBS yang akan diterapkan di rumah tangga masyarakat. Kesepuluh unsur tersebut adalah:

1. Persalinan ditolong oleh tenaga kesehatan

2. Memberi bayi ASI eksklusif

3. Menimbang balita setiap bulan

4. Menggunakan air bersih

5. Mencuci tangan pakai sabun

6. Menggunakan jamban sehat

7. Memberantas jentik di rumah

8. Makan buah dan sayur setiap hari

9. Melakukan aktifitas fisik setiap hari

10. Tidak merokok di dalam rumah. 
Aulia, D. et al. Media Promosi Perilaku Hidup Bersih Dan Sehat (PHBS) Di Kawasan Wisata Danau Toba

\section{PENUTUP}

\section{Kesimpulan}

1. Program kemitraan ini telah memperoleh bahan-bahan untuk pembuatan media promosi PHBS dengan melibatkan masyarakat dana toba-samosir.

2. Media promosi PHBS yang diberikan dapat meningkatkan kapasitas pengetahuan tentang perilaku hidup bersih dan sehat.

3. Seluruh masyarakat sudah melakukan persalinan dengan bantuan tenaga kesehatan di Desa Pardomuan.

4. Media promosi PHBS dalam program kemitraan ini dibuat dalam bentuk buku panduan PHBS, video promosi PHBS dan banner PHBS.

\section{Saran}

1. Kepada masyarakat agar selalu berpartisipasi aktif dalam menerapkan PHBS rumah tangga di lingkungan sekitar.

2. Perlu adanya kegiatan yang lebih rutin tentang penyuluhan PHBS maupun pelatihan PHBS di lingkungan sekolah setempat dari pihak kesehatan.

3. Kepada pemerintah, untuk memberikan perhatian yang lebih besar terutama dalam pengadaan air bersih dan fasilitas sanitasi yang sehat.

\section{REFERENSI}

[1] Achmadi, Umar Facmi. 2005. Manajemen Kesehatan Berbasis Wilayah. Kompas: Jakarta

[2] Ayu, Sri Fajar, dkk. 2016. Improving Clean and Healthy Living Behavior in the Poor Communities in Coastal Area, Serdang Bedagai. Advances in Health Research volume 1. Atlantis Press

[3] Syahrial, Eddy, dkk. Health Promotion Management Model in Dealing with Tropical Disease. Advances in Health Research volum 1. Atlantis Press 